\title{
VULNERABILIDADE AMBIENTAL E DESERTIFICAÇÃO: A CORRELAÇÃO ESPACIAL MULTITEMPORAL COM A TEMPERATURA DE SUPERFÍCIE
}

\author{
$\underline{\text { Iolanda Santos de Castró }}{ }^{\text {; Jocimara Souza Britto Lobão²}}{ }^{2}$ Israel de Oliveira \\ Junior $^{3}$ e Diego Pereira Costa ${ }^{4}$ \\ 1. Graduanda do curso de Licenciatura em Geografia, Departamento de Ciências \\ Humanas e Filosofia (DCHF), UEFS, e-mail: iolycastro@ hotmail.com \\ 2. Orientadora, Docente do curso de Geografia, DCHF, UEFS, e-mail: \\ juci.lobao@gmail.com \\ 3.Doutorando e Professor de Geografia, e-mail: iojjunior@gmail.com \\ 4. Mestrando em Ciências ambientais, UEFS, Feira de Santana-BA, \\ e-mail: costapdiego@gmail.com
}

PALAVRAS-CHAVE: Degradação, Desertificação, Temperatura de superfície

\section{INTRODUÇÃO}

O Nordeste brasileiro e a Região Semiárida são caracterizados pela região da pobreza e de problemas socioambientais, socioeconômicos de desigualdades regionais, marcado pela fome, seca sendo uma região de miséria e pobreza; apresentando baixa escolaridade e renda, altos índices de analfabetismo, a migração para os centros urbanos, escassez ao acesso a rede d'água, saúde, escola, moradia, entre outros. Além das desigualdades decorrentes de questões econômica e social, a região é também afetada pela degradação/desertificação da terra pela ação humana.

A região semiárida nordestina é caracterizada pela ocorrência de diversas variáveis que se associam à desertificação, dentre as principais destacam-se: os baixos índices pluviométricos, a irregularidade das precipitações no tempo e no espaço; a ocorrência de ventos quentes e secos; a intermitência sazonal das drenagens; a forte incidência de radiação solar; a baixa capacidade de retenção de água; a antiga e intensa ocupação da terra; a utilização de técnicas rudimentares de uso do solo; e a marginalidade cultural, política e econômica de sua população (OLIVEIRA-GALVÃO \& SAITO, 2003).

O Polo regional de Jeremoabo integra a região semiárida baiana, que exibe em seu território técnicas e práticas de uso inadequados de sua terra como pastagem, extração da vegetação, da mineração aceleram o processo de desertificação, a qual ocorre de forma insustentável comprometendo as alterações climáticas e a dinâmica social (OLIVEIRA JUNIOR, 2014). A caracterização dos meios biofísicos e socioeconômicos, das análises dos níveis quantitativos das relações produtivas, a presença de solos rasos de superfície arenosa, chuvas irregulares, pobreza, baixa escolaridade e renda, desemprego, dentre outros, confirmando assim a vulnerabilidade que a região vem sofrendo (BRASIL, 2005; LOBÃO; SILVA, 2013). O objetivo desta pesquisa analisar a temperatura de superfície numa série histórica de 17 anos com a finalidade de identificar indicadores ambientais à desertificação. 


\section{MATERIAI E MÉTODOS}

O presente estudo abrange o Polo regional de Jeremoabo-BA, localizado ao norte da Bahia, aproximadamente a 24.560,67 km² de extensão (PAE-BA, 2014); incorpora os municípios (Antas, Canudos, Chorrochó, Coronel João de Sá, Glória, Jeremoabo, Macururé, Novo Triunfo, Paulo Afonso, Pedro Alexandre, Rodelas, Santa Brígida e Uauá) (Mapa 01).

Mapa 01 - Localização da área de estudo

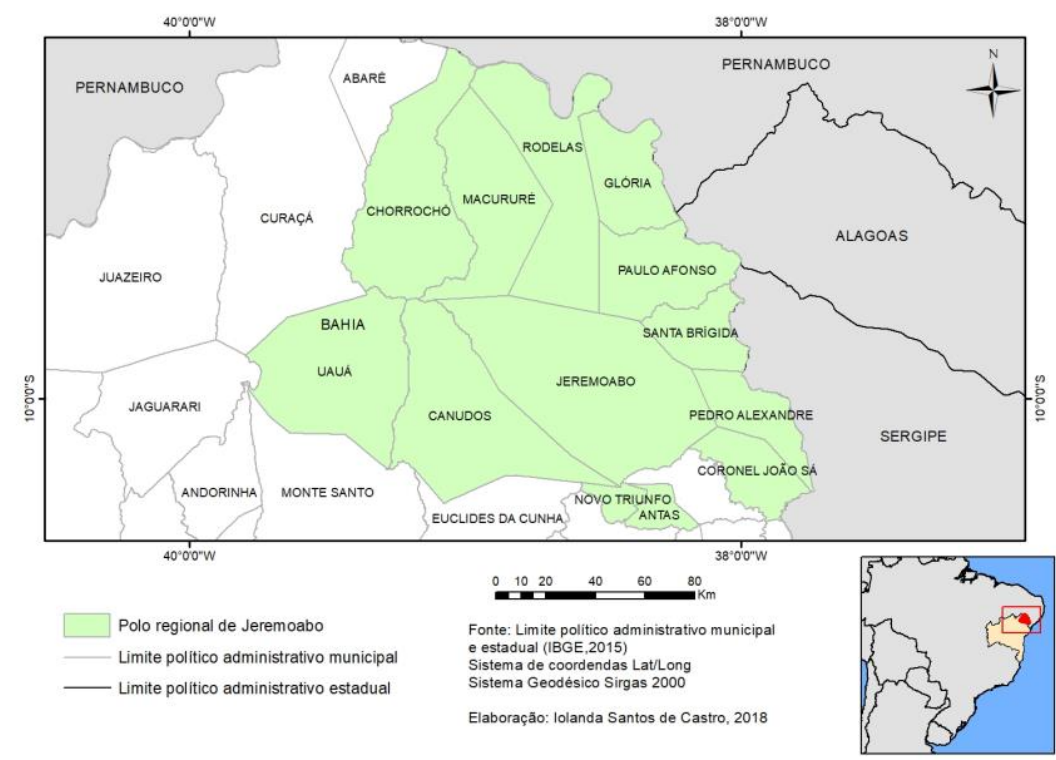

As análises estatísticas dos resultados foram feitas pela correlação linear (Pearson) medindo a relação entre as duas variáveis. Para o cálculo do coeficiente aplicou-se a fórmula $\mathbf{p}=\mathbf{r}^{\mathbf{2}} \mathbf{. 1 0 0}$ para avaliar a relação dos valores atribuídos. Com os dados do mapa de Temperatura e de degradação, foi gerado o gráfico de dispersão de Pearson - forma de análise de relação que envolve dados contínuos, sintetizados pelo coeficiente de correlação " $r$ de Pearson" a distribuição de frequência conjunta de x e y chama-se distribuição normal bivariada, o valor $r$ varia de -1.00 a + 1.00 (STEVENSON, 1981).

\section{RESULTADOS E/OU DISCUSSÃO (ou Análise e discussão dos resultados)}

Nos estudos sobre a desertificação, a Temperatura de Superfície refere-se a um indicador importante para a compreensão das questões ambientais. A importância em realizar uma análise multitemporal enfocando o indicador temperatura de superfície, pode ser considerada um dos fatores essenciais do clima, para indicar ou não se há incidência de desertificação mediante este parâmetro, além disso, pode contribuir como medidas mitigadoras conservacionistas adequadas à região. O Polo de Jeremoabo - BA apresentou alterações significativa de temperatura de superfície, conforme os mapas analisados no período de 2000-2016, (Figura 01).

Figura 01 - Análise multitemporal das médias anuais da Temperatura de Superfície no período de 2000-2016 do Polo regional de Jeremoab0-BA 


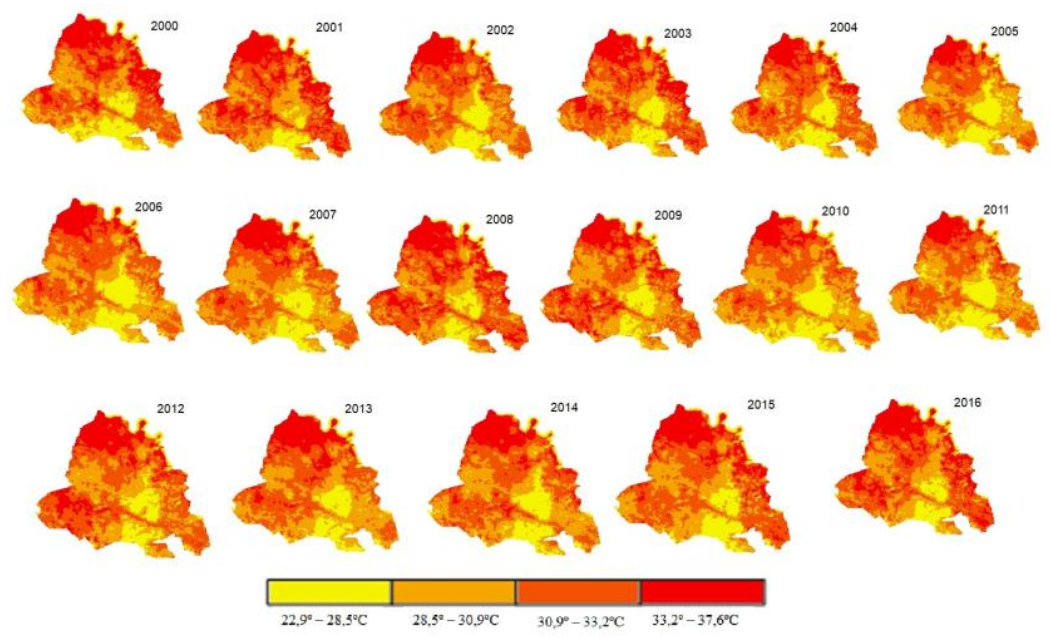

Elaboração: Iolanda Santos de Castro, 2018

$\mathrm{Na}$ análise em questão as maiores temperaturas máximas ocorreram nos anos de 2015 , 2013 e 2012 , correspondendo a $41^{\circ} \mathrm{C}, 40,5^{\circ} \mathrm{C}$ e $40,3^{\circ} \mathrm{C}$, respectivamente e as menores nos anos de 2008 e 2009 com $37^{\circ} \mathrm{C}$ e $37,1^{\circ} \mathrm{C}$, respectivamente (tabela 1, gráfico 1). Considerando as temperaturas mínimas os anos de 2000, 2007 e 2009 destacam-se com os menores valores $22,9^{\circ} \mathrm{C}, 22,1^{\circ} \mathrm{C}$ e $23,1^{\circ} \mathrm{C}$, respectivamente e $2015 / 2016$ com os maiores $41^{\circ} \mathrm{C}$ e $39,2^{\circ} \mathrm{C}$, respectivamente (tabela 1 , gráfico 1 ). As temperaturas médias anuais dos anos analisados não ultrapassaram $33,3^{\circ} \mathrm{C}$, atingindo $30,4^{\circ} \mathrm{C}$ em 2006 , demonstrando uma amplitude de cerca de $3^{\circ} \mathrm{C}$ nos dezessete anos.

As investigações acerca do processo de desertificação tendo em vista o indicador de temperatura de superfície e vulnerabilidade à degradação, consistiu numa correlação fraca positiva (Levin e Fox, 2004) variando de mínima de Pearson ( $\mathrm{r}=0,31359)$ a máxima de Pearson $(r=0,44839)$, a primeira, refere-se ao ano de 2001 e a última, ao ano de 2006. Estas comprovações estão espacializadas (gráfico 1).

Gráfico 01 - Correlação da Temperatura de Superfície e Degradação dos anos de 2000 a 2016

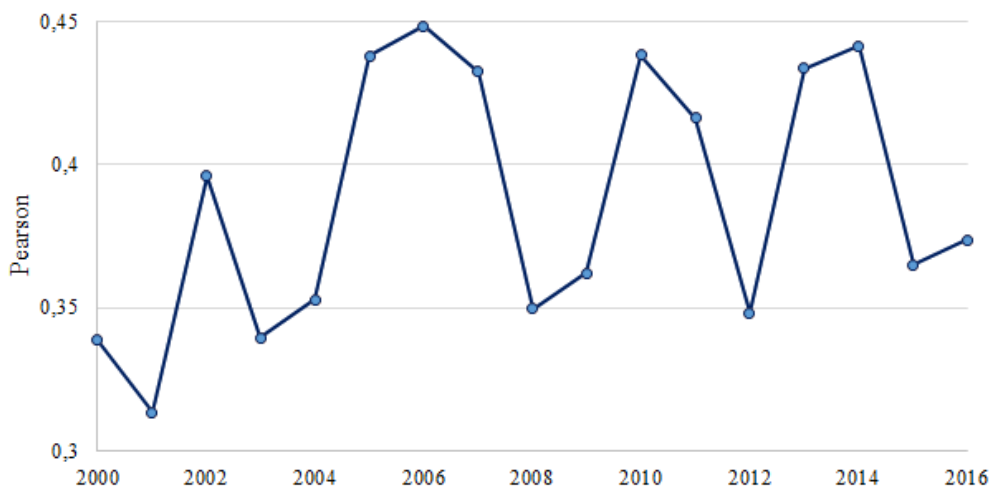

Elaboração: Iolanda Santos de Castro, 2018

Pautado nesta temática, a correlação entre as variáveis estudadas (gráfico 2) evidenciou que no ano de 2001 ocorreu um menor índice de Pearson de $(r=0,3135)$, já no de 2006, 
este índice correspondeu a $(\mathrm{r}=0,4483)$, enquanto que no último ano da pesquisa, o índice foi $(r=0,3737)$. O estudo das variáveis analisadas demonstrou uma correlação fraca positiva. Assim, estas variáveis quando analisadas movem-se em direção oposta, de forma que analisando o gráfico de forma isolada à primeira vista tende-se a indicar em que a medida que a degradação aumenta a temperatura de superfície diminui. Entretanto, verifica-se que espacialmente há uma similaridade entre as áreas degradas e as maiores temperaturas.

\section{CONSIDERAÇÕES FINAIS (ou Conclusão)}

O estudo das variáveis analisadas por meio de gráficos de Dispersão Pearson demonstrou uma correlação fraca positiva, o que não invalida as análises realizadas. Entretanto, alguns aspectos devem ser ressaltados como, o mapa de vulnerabilidade à degradação foi elaborado a partir da síntese de outros mapas (Uso e ocupação, solos, índice de vegetação e declividade), logo, os dados são potencializados e/ou amenizados em função do grau de pertinência inferido pelo analista, o que pode influenciar na correlação com os dados de temperatura.

Sendo assim, este trabalho contribui para um Projeto maior que estuda o processo de desertificação no polo a partir de indicadores e em seus dados já apontam áreas mais degradadas fazendo-se necessário medidas mitigadoras afim de nortear planejamento ambiental para enfrentar o processo de vulnerabilidade à desertificação desses municípios Antas, Macururé, Rodelas, Novo Triunfo e também de outros no Polo Regional de Jeremoabo.

\section{REFERÊNCIAS}

BRASIL. Ministério do Meio Ambiente. Programa de ação nacional de combate à desertificação. Brasília, 2005.

LOBAO, J. S. B.; SILVA, B.C.M.N. Análise socioambiental na região semiárida da Bahia: geoprocessamento com subsidio ao ordenamento territorial. Feira de Santana: UEFS, p.353, 2013.

LEVIN, J.; FOX, J.A. Estatística para ciências humanas. São Paulo, Pearson Prentice Hall, 2004.

OLIVEIRA GALVÃO. A.L.C.de; SAITO. C.H. Mapeamentos sobre Desertificação no Brasil: uma análise comparativa. No 77. Agosto de 2003.

OLIVEIRA JUNIOR, I. O processo de desertificação: a vulnerabilidade e a degradação ambiental no polo regional de Jeremoabo - Bahia. Dissertação (Mestrado em Geografia) - Programa de Pós-Graduação em Geografia, Instituto de Geociências, Universidade Federal da Bahia, Salvador, 2014.

PAE/BA - Plano Estadual de Combate à Desertificação e Mitigação dos Efeitos da Seca. Versão validada. Salvador, 2014.

STEVENSON, W. J. Estatística aplicada à Administração. São Paulo: Harbra, 1981. 